\title{
Hepatic Resection and Transplantation for Peripheral Cholangiocarcinoma
}

\author{
F. Adrian Casavilla, MD, FACS ${ }^{*}$, J. Wallis Marsh, MD, FACS ${ }^{*}$, Shunzaburo Iwatsuki, MD, PhD, \\ FACS $^{\star}$, Satoru Todo, MD, FACS ${ }^{\star}$, Randall G. Lee, MD $\dagger$, Juan R. Madariaga, MD, FACS ${ }^{\star}$, \\ Antonio Pinna, MD*, Igor Dvorchik, PhD*, John J. Fung, MD, PhD, FACS ${ }^{*}$, and Thomas E. \\ Starzl, MD, PhD, FACS \\ *Department of Surgery, the Thomas E. Starzl Transplantation Institute, University of Pittsburgh \\ Medical Center, Pittsburgh, PA. \\ tDepartment of Pathology, the Thomas E. Starzl Transplantation Institute, University of Pittsburgh \\ Medical Center, Pittsburgh, PA.
}

\begin{abstract}
Background-Recent publications have questioned the role of orthotopic liver transplantation (OLT) in treating advanced or unresectable peripheral cholangiocarcinoma (Ch-Ca).

Study Design-We reviewed our experience with $\mathrm{Ch}-\mathrm{Ca}$ to determine survival rates, recurrence patterns, and risk factors in 54 patients who underwent either hepatic resection or OLT between 1981 and 1994. Liver transplantation was performed in patients with unresectable tumors $(\mathrm{n}=12)$ and in those with advanced cirrhosis $(\mathrm{n}=8)$. There were 33 women $(61 \%)$ and 21 men $(39 \%)$, with a mean age of 54.3 years. The median followup period was 6.8 years. Prognostic risk factors were analyzed by univariate and multivariate analyses.
\end{abstract}

Results-Mortality within 30 days was 7.4\%. Overall patient and tumor-free survival rates were $64 \%$ and $57 \%$ at 1 year, $34 \%$ and $34 \%$ at 3 years, and $26 \%$ and $27 \%$ at 5 years after operation. Thirtytwo patients $(59.3 \%)$ experienced tumor recurrence. Univariate analysis revealed that multiple tumors, bilobar tumor distribution, regional lymph node involvement, presence of metastasis, positive surgical margins, and advanced pTNM stages were significant negative predictors of both tumor-free and patient survival. Multivariate analysis revealed that positive margins, multiple tumors, and lymph node involvement were independently associated with poor prognosis. When patients with these three negative predictors were excluded, the patient survivals at 1,3 , and 5 years were $74 \%, 64 \%$, and $62 \%$, respectively.

Conclusions-Both hepatic resection and OLT are effective therapies for $\mathrm{Ch}-\mathrm{Ca}$ when the tumor can be removed with adequate margins, the lesion is singular, and lymph nodes are not involved.

Peripheral or intrahepatic cholangiocarcinoma (Ch-Ca) is second (10-20\%) only to hepatocellular carcinoma (70-80\%) as the most common primary malignancy of the liver. Currently, non-surgical therapeutic modalities for $\mathrm{Ch}-\mathrm{Ca}$ are ineffective. Hepatic resection (partial hepatectomy) has been the conventional form of potentially curative treatment (1-5); the possibility of extending extirpation to total hepatectomy (6-8) or upper-abdominal exenteration (9-11) followed by liver replacement has been controversial (12-16). 
The objective of this study was to review our experience with Ch-Ca to determine survival rates, recurrence patterns, and prognostic risk factors in patients who had undergone liver resection or hepatic transplantation.

\section{Methods}

During the 14-year period of 1981-1994, 54 patients with Ch-Ca underwent either hepatic resection $(\mathrm{Hx})(\mathrm{n}=34)$ or orthotopic liver transplantation $(\mathrm{OLT})(\mathrm{n}=20)$ at the University of Pittsburgh Medical Center. The median followup was 6.8 years (range, 1.3-14.9 years). There were 33 women (61\%) and 21 men (39\%); ages ranged from 28 to 75 years (mean \pm SE, 54.3 \pm 11.4 years).

\section{Clinicopathologic characteristics}

For this study, Ch-Ca was defined as a carcinoma arising from the epithelium of the intrahepatic bile duct (intrahepatic or peripheral type). For patients in whom the anatomic classification was ambiguous, the presence of severe epithelial dysplasia or carcinoma in situ of the extrahepatic duct was taken as an indication of hilar $\mathrm{Ch}-\mathrm{Ca}$. These patients were not included in the study.

The pathology reports and operative findings were used to determine the following: principal tumor size (diameter in $\mathrm{cm}$ ), number of gross hepatic lesions (single or multiple), lobar distribution (unilobar or bilobar), vascular invasion $\left(\mathrm{V}_{0}=\right.$ none; $\mathrm{V}_{1}=$ microscopic; $\mathrm{V}_{2},=$ macroscopic), lymphatic invasion (positive or negative), surgical margins (positive or negative), distant metastases (present or absent), and cirrhosis (present or absent).

Tumor stage was defined according to the pTNM classification proposed by the International Union Against Cancer (17) and the American Joint Committee on Cancer (18) (Table 1). There were 12 patients with stage I or II tumors, 15 patients with stage III tumors, and 27 patients with stage IV tumors (Table 2).

\section{Surgical procedures}

For those with anatomically resectable tumors or for those without advanced, cirrhosis, partial hepatectomy $(\mathrm{Hx})$ was the procedure of choice. Total hepatectomy with liver replacement (OLT) was performed when tumor extension or underlying cirrhosis precluded partial hepatectomy.

Thirty-four patients were treated with Hx: nine underwent left lobectomy, eight had a right lobectomy, six had right trisegmentectomy, four underwent left trisegmentectomy, three had an extended left lobectomy, two had an extended right lobectomy, and two underwent large nonanatomic resections. The surgical techniques of subtotal hepatectomy have been described elsewhere (19-22).

Twenty patients were treated with OLT. Twelve had unresectable tumor(s) by conventional techniques of subtotal hepatectomy and had transplantation; eight had transplantation because of concomitant advanced cirrhosis. Because of highly unfavorable conditions such as lymph node involvement or direct invasion of tumor into adjacent organs, an upper-abdominal exenteration and organ-cluster transplantation (OLT-Cl) were performed in 9 of the 20 patients $(9,10)$. The surgical technique for OLT, including OLT-Cl, and the immunosuppression used thereafter have been described elsewhere $(9,23-25)$. 


\section{Adjuvant therapy}

Thirty-seven patients received adjuvant chemotherapy or radiation therapy before or after the operation (Table 3). Because of the prolonged study period, these regimens were highly variable.

\section{Statistical analysis}

The results were summarized as of December 31, 1996. Cumulative overall survival and tumorfree survival rates were calculated by the method of Kaplan and Meier, with adjustment for the type of operation (OLT versus Hx) (26). If a patient died at any time without tumor recurrence, he or she was censored as tumor-free at that time for the Kaplan-Meier method. Alternatively, if a patient died with tumor recurrence, that patient was considered an uncensored observation for the tumor-free survival analysis. Potential risk factors examined by univariate analysis were age, gender, tumor size, number of lesions, lobar involvement, vascular invasion, lymph node involvement, distant metastases, pTNM stage, surgical margins, presence or absence of associated cirrhosis of the liver, and adjuvant therapy. Values of $p<$ 0.05 were considered significant. The Cox proportional hazard regression model was used to assess the relative prognostic influence on survival.

\section{Results}

\section{Pathologic characteristics}

The principal tumor size had a median diameter of $8.3 \mathrm{~cm}$ (mean $\pm \mathrm{SE}, 8.1 \pm 4.2 \mathrm{~cm}$ ), with a range of $0.8-22 \mathrm{~cm}$. Twenty-six patients (48\%) had a single tumor; the remaining 28 patients $(52 \%)$ had multiple tumors. The tumors were unilobar in 27 patients; 14 had only right lobe involvement, and 13 had only left lobe involvement (Table 3 ).

Fifteen patients (28\%) had no evidence of vascular invasion $\left(\mathrm{V}_{0}\right), 32$ patients $(59 \%)$ had microscopic invasion $\left(\mathrm{V}_{1}\right)$, and 7 patients $(13 \%)$ had gross vascular invasion $\left(\mathrm{V}_{2}\right)$ of either the portal vein (4 patients) or the hepatic vein branches (3 patients).

Fourteen patients (26\%) had regional lymph node involvement (N-1) and five (9\%) had regional metastatic disease (M-1) at the time of operation (Table 3). All lesions were resected in continuity with the principal tumor.

The margins of resection were free of tumor $\left(\mathrm{R}_{0}\right)$ in 40 patients. Margins were microscopically positive $\left(R_{1}\right)$ in 10 patients and grossly positive $\left(R_{2}\right)$ in the remaining 4 (Table 3 ). No gross tumor remained at the conclusion of the surgical procedure in any patient.

Eight patients in the OLT group had associated cirrhosis of the liver (40\%). Of the 29 patients tested for hepatitis B virus, 3 had positive serology. None of the 20 patients tested was positive for hepatitis $\mathrm{C}$ virus. One of 20 patients tested had an elevated serum titer of carcinoembryonic antigen; 3 of the 24 tested for serum alpha-fetoprotein had elevated levels.

The pTNM stages of the 54 patients are summarized in Tables 2 and 3. Twenty-seven patients (50\%) presented with pTNM stage IV.

\section{Survival rate}

The overall patient survival rates of the 54 patients were $64 \%$ at 1 year, $34 \%$ at 3 years, and $26 \%$ at 5 years after operation (Fig. 1). The tumor-free survival rates were $57 \%$ at 1 year, $34 \%$ at 3 years, and $27 \%$ at 5 years after operation (Fig. 1). 
The patient survival rates after $\mathrm{Hx}(60 \%$ at 1 year, $37 \%$ at 3 years, and $31 \%$ at 5 years) were similar to those after OLT (70\% at 1 year, $29 \%$ at 3 years, and $18 \%$ at 5 years), as shown in Figure 2. Tumor-free survival after $\mathrm{Hx}(50 \%$ at 1 year, $30 \%$ at 3 years, and $25 \%$ at 5 years) was also similar to that after OLT ( $67 \%$ at 1 year, $31 \%$ at 3 years, and $31 \%$ at 5 years), as shown in Figure 3. The higher rate of tumor-free survival compared with actuarial patient survival reflects a high death rate without recurrence among patients with $\mathrm{Ch}-\mathrm{Ca}$, regardless of the type of surgical procedure.

As expected, the pTNM stage significantly influenced both patient and tumor-free survival (Fig. 4; Table 3).

\section{Causes of death}

Twenty-four of the 34 patients (73.5\%) in the Hx group and 16 of the 20 patients (80\%) in the OLT group were dead at the time of followup (December 1996).

Four of the 54 patients died within 30 days after operation, giving an overall operative mortality rate of $7.4 \%$. The first patient died intraoperatively of an irreversible arrhythmia during $\mathrm{Hx}$, and the second patient died of sepsis and liver failure 24 days after Hx. The third patient died of massive upper gastrointestinal hemorrhage 6 days after OLT, and the fourth patient died of rupture of a mycotic hepatic artery aneurysm 18 days after OLT.

An additional six patients died of causes unrelated to $\mathrm{Ch}-\mathrm{Ca}$. One patient died of renal and cardiac failure 19 months after $\mathrm{Hx}$, the second died of an unknown sudden cause 6 years after $\mathrm{Hx}$, and the third patient died of pancreatic cancer 14 years after Hx. The fourth patient died of acute pulmonary tuberculosis 5 months after OLT, the fifth patient died of aspergillosis 14 months after OLT, and the sixth died of recurrent hepatitis B 22 months after OLT.

A total of 30 patients died with recurrent $\mathrm{Ch}-\mathrm{Ca}, 19(55 \%)$ in the Hx group and $11(56 \%)$ in the OLT group. The higher 5-year tumor-free survival in the OLT group relative to the Hx group (31\% and $25 \%$, respectively) was due to the low rate of tumor recurrence among the 9 OLT-Cl patients (Fig. 3).

\section{Prognostic factors}

The influence of the 12 clinicopathologic factors on tumor-free and overall patient survival was examined by univariate analysis (Table 3 ). Multiple gross tumors, a bilobar tumor distribution, regional lymph node involvement, the presence of metastasis, positive surgical margins, and advanced (III and IV) pTNM stages were statistically significant negative prognostic factors for both tumor-free and overall patient survival. The presence of vascular invasion was a statistically significant factor reducing the tumor-free survival, but it did not influence the overall patient survival. Age, gender, size of principal tumor, associated cirrhosis, and adjuvant chemotherapy did not influence either tumor-free or patient survival.

Because positive metastasis turned out to be uniformly fatal (all five patients died within 1.3 years) ( $\mathrm{p}<0.001$ ), this prognostic factor was excluded from the multivariate analysis. Of the six prognostic factors that reached statistical significance in the univariate analysis, the multivariate analysis revealed positive margins, multiple tumors, and lymph node involvement to be independently associated with a poor prognosis both for patient and for longterm (more than one year) tumor-free survival. For patient survival, the relative hazards for positive margins, multiple tumors, and lymph node involvement were 1.74, 1.63, and 1.60, respectively. For tumor-free survival, the relative hazards for positive margins, multiple tumors, and lymph node involvement were 8.2,2.0, and 2.65, respectively. These statistics show the hazard of death or tumor recurrence at any given time point. 
There were 21 patients ( 15 in the Hx group and 6 in the OLT group) in whom none of these three negative predictors was present. The actuarial patient and tumor-free survival rates of these 21 patients (low-risk group) were $74 \%$ and $79 \%$ at 1 year, $64 \%$ and $62 \%$ at 3 years, and $64 \%$ and $52 \%$ at 5 years, respectively (Fig. 5). Conversely, in the 33 patients (19 in the Hx group and 14 in OLT group) in whom at least one of these three negative predictors was present (high-risk group), patient and tumor-free survival rates were 58\% and $43 \%$ at 1 year, $18 \%$ and $13 \%$ at 3 years, and $9 \%$ and $13 \%$ at 5 years after operation $(\mathrm{p}<0.0001)$ (Fig. 5).

\section{Tumor recurrence}

Recurrence of Ch-Ca was confirmed in 32 of the 54 patients (59\%) during the study period: 21 of the 34 patients (62\%) in the Hx group and 11 of the $20(55 \%)$ in the OLT group (2 patients are currently alive with disease). Tumor recurrence was diagnosed within 1 year after operation in 21 patients $(66 \%)$ and within 2 years in 29 patients $(91 \%)$. Only one patient with recurrence had it after 3 years; this patient was in the resection group and suffered recurrence at 4.3 years. Overall, there was no difference in time to recurrence between Hx and OLT.

The liver was the most common site of tumor recurrence ( 20 patients), followed by the lung (18 patients), the bones ( 7 patients), and other sites such as the peritoneum, adrenal gland, and kidney (5 patients).

\section{Five-year survivors}

Of the 39 patients with $\geq 5$ years of followup, 9 (23\%) survive: 6 of 21 (29\%) in the Hx group and 3 of $18(17 \%)$ in the OLT group. Seven of these 9 patients had a single tumor; 6 had a unilobar tumor distribution, and 7, surprisingly, had a principal tumor size of $>5 \mathrm{~cm}$. Four of the 9 patients had microscopic vascular invasion. Four of the 9 patients were classified as pTNM stage I or II, 3 patients as stage III, and 2 patients as stage IVA.

None of the 5-year survivors had positive margins, regional metastasis, lymph node involvement, or macroscopic vascular tumor invasion. All three patients in the OLT group who survived > 5 years were classified as PTNM stage III or IVA and underwent OLT-Cl. Two of the 5-year survivors (both in the Hx group) had tumor recurrence in the liver 2 and 4 years after $\mathrm{Hx}$ and underwent repeat surgical resection.

\section{Discussion}

Cholangiocarcinoma is a cancer arising from the epithelium of the biliary ducts. The bile duct located on the hepatic side of the first intrahepatic branch of the right and left hepatic duct is considered "intrahepatic" or "peripheral." The remaining part of the bile duct is considered "extrahepatic," including the hilum of the liver. In the strictest sense, then, Ch-Ca is a cancer arising from the epithelium of the intrahepatic duct or ductules (27-29). Practically speaking, differentiation of intrahepatic from extrahepatic bile duct cancer is often difficult anatomically, particularly in the hepatic hilum, and the histologic characteristics of the two are identical. For these reasons, cancers arising from the epithelium of the right and left hepatic ducts and the bifurcation are also called Ch-Ca of "hilar" or "central" type (Klatskin tumor) (30).

This article reports the prognostic risk factors and outcomes of 54 patients with Ch-Ca who underwent aggressive surgical therapy at our institution. To our knowledge, this study represents the largest series of patients with peripheral $\mathrm{Ch}-\mathrm{Ca}$ who were treated with $\mathrm{Hx}$ or OLT at a single institution. These two groups of patients treated with two different surgical procedures are not strictly comparable because $\mathrm{Hx}$ was considered the surgical procedure of choice for resectable $\mathrm{Ch}-\mathrm{Ca}$, and OLT was performed when patients had either unresectable tumors or associated cirrhosis. It was surprising, then, to find that even though a significantly 
greater number of patients in the OLT group had advanced malignant disease than in the Hx group ( $65 \%$ versus $41 \%$ ), as represented by stage IV disease (Table 2 ), the longterm tumorfree and patient survival rates were similar for the two groups. Although patient survival at 5 years was greater in the Hx group, the 5-year tumor-free survival was greater in the OLT group ( $31 \%$ versus $25 \%$ ), despite the more advanced disease. The dramatic decrease in survival for the OLT group between 3 and 5 years was due to two deaths related to early recurrence.

This study confirmed the general opinion $(13,14,31,32)$ that postoperative recurrence rates and survival of patients with $\mathrm{Ch}-\mathrm{Ca}$ are determined by pTNM stage. The median survival after Hx or OLT for tumor stages I and II combined, III, and IV was 77, 18, and 17.5 months, respectively. The actuarial 1-, 3-, and 5-year patient survival rates were $90 \%, 70 \%$, and $70 \%$ for stages I and II; $60 \%, 33.3 \%$, and $25 \%$ for stage III; and $55.6 \%, 21.6 \%$, and $13 \%$ for stage IV. These rates are consistent with previous reports of patients undergoing liver resection for Ch-Ca $(3,13,14)$. Unfortunately, an accurate analogy with published data for patients who underwent OLT for $\mathrm{Ch}-\mathrm{Ca}$ is extremely difficult to make because case material was small $(12,14,31,32)$, results were not stratified according to specific stages (31-33), or the two distinctive types of $\mathrm{Ch}-\mathrm{Ca}$ (peripheral versus hilar) were combined in the analysis (12).

The actuarial survival of patients undergoing Hx or OLT for Ch-Ca, reported in this study, is comparable to our results (34) using similar surgical treatment in patients with hepatocellular carcinoma at equivalent stages. There were more 5-year survivors treated for $\mathrm{Ch}-\mathrm{Ca}$ than those treated for hepatocellular carcinoma ( $23 \%$ versus $14 \%$, respectively). Positive tumor margins and lymph node metastasis were prognostic risk factors associated with significantly poorer survival rates for both types of malignancies.

The results of this study suggest, in contrast to reports in the literature, that OLT should not be eliminated in the treatment of Ch-Ca. In fact, based on our identification of a selected group of patients found to have an "acceptable" longterm survival, an argument could be made for expanding its role if there is a sufficient supply of donor organs. At least one group has questioned whether OLT-Cl is of any value for the treatment of hepatobiliary malignancies in general (16). Although there is limited experience with the cluster procedure for the specific indication of $\mathrm{Ch}-\mathrm{Ca}$, our only patients with $\mathrm{Ch}-\mathrm{Ca}$ in the OLT group who survived $>5$ years had undergone OLT-Cl. Of nine patients who underwent OLT-Cl, only four had recurrent disease during the study period.

Our multivariate analysis revealed that, in addition to metastatic disease, positive surgical margins, multiple gross tumors, and lymph node involvement were independent risk factors for poor survival after both $\mathrm{Hx}$ and OLT in patients with $\mathrm{Ch}-\mathrm{Ca}$. Conversely, the actuarial 1-, 3 -, and 5-year survival rates of patients with none of these three negative predictors were significantly higher than those of patients with at least one of these risk factors $(74.2 \%, 66.5 \%$, and $66.5 \%$ versus $58 \%, 18 \%$, and $9 \%$, respectively). Because we did not find any difference in time to recurrence between the Hx and OLT groups, our results do not support the hypothetical (and logical) contention that immunosuppression shortens the tumor-free interval rate. The indications for OLT can reasonably include at least some appropriately staged patients with Ch-Ca.

In conclusion, these data suggest that Hx and OLT are both defensible options for patients with Ch-Ca who have single lesions, negative lymph nodes, and surgically resectable disease. Identification of risk factors, which predict prognosis, requires extensive preoperative and intraoperative evaluations. Because the number of patients undergoing surgical therapy for this disease is so small, a multiinstitutional study is needed to assess the relative efficacy of $\mathrm{Hx}$, conventional OLT, or even upper-abdominal exenteration and OLT (OLT-Cl). Conceivably, 
the indications for conventional OLT or OLT-Cl should be broadened to include some of the patients with advanced disease who are currently being treated with Hx.

\section{References}

1. Kamiyama, Y.; Tobe, T. Treatment of primary liver cancer in Japan. In: Okuda, K.; Ishak, KG., editors. Neoplasms of the Liver. Tokyo: Springer-Verlag; 1987. p. 375-380.

2. Iwatsuki S, Sheahan DG, Starzl TE. The changing face of hepatic resection. Curr Probe Surg 1989;26:283-379.

3. Chen MF, Jan YY, Wang CS, et al. Clinical experience in 20 hepatic resections for peripheral cholangiocarcinoma. Cancer 1989;64:2226-2232. [PubMed: 2553242]

4. Chu KM, Lai ECS, Al-Hadeedi S, et al. Intrahepatic cholangiocarcinoma. World J Surg 1997;21:301306. [PubMed: 9015175]

5. Madariaga JR, Iwatsuki S, Todo S, et al. Liver resection for hilar and peripheral cholangiocarcinomas: a study of 62 cases. Ann Surg. (in press).

6. Starzl, TE. Hepatic malignancy. In: Starzl, TE., editor. Experience in Hepatic Transplantation. Philadelphia: WB Saunders; 1969. p. 4-8.(with the assistance Putnam CW).

7. Calne, RY. Indications and assessment for orthotopic liver transplantation. In: Calne, RY., editor. Liver Transplantation. The Cambridge-King's College Hospital Experience. London: Grune \& Stratton; 1983. p. 59-62.

8. Iwatsuki S, Gordon RD, Shaw BW, et al. Role of liver transplantation in cancer therapy. Ann Surg 1985;202:401-407. [PubMed: 2996449]

9. Starzl TE, Todo S, Tzakis A, et al. Abdominal organ cluster transplantation for the treatment of upper abdominal malignancies. Ann Surg 1989;210:374-386. [PubMed: 2673085]

10. Tzakis A, Ricordi C, Alejandro R, et al. Pancreatic islet transplantation after upper abdominal exenteration and liver replacement. Lancet 1990;336:402-405. [PubMed: 1974944]

11. Alessiani M, Tzakis A, Todo S, et al. Assessment of five-year experience with abdominal organ cluster transplantation. J Am Coll Surg 1995;180:1-9. [PubMed: 8000645]

12. Goldstein RM, Stone M, Tillery GW, et al. Is liver transplantation indicated for cholangiocarcinoma? Am J Surg 1993;166:768-772. [PubMed: 8273866]

13. Pichlmavr R, Lamesch P, Weimann A, et al. Surgical treatment of cholangiocellular carcinoma. World J Surg 1995;19:83-88. [PubMed: 7740815]

14. Washburn WK, Lewis D, Jenkins RL. Aggressive surgical resection for cholangiocarcinoma. Arch Surg 1995;130:271-276.

15. Berdah SV, Delpero JR, Garcia S, et al. A Western surgical experience of peripheral cholangiocarcinoma. Br J Surg 1996;83:1517-1521. [PubMed: 9014664]

16. Knechtle SJ, Kalavoglu M, D’Alessandro AM, et al. Should abdominal cluster transplantation be abandoned? Transplant Proc 1993;25:1361-1363. [PubMed: 8442141]

17. Hermanek, P.; Sobin, LH., editors. TNM Classification of Malignant Tumors. 4th ed. Berlin: SpringerVerlag; 1987. p. 53-55.

18. Bearhs, OH.; Henson, DE.; Hutter, RVP.; Kennedy, BJ., editors. American Joint Committee on Cancer. Manual for Staging of Cancer. 4th ed. Philadelphia: JB Lippincott; 1992. p. 89-100.

19. Starzl TE, Bell RH, Beart RW, Putnam CW. Hepatic trisegmentectomy and other liver resections. Surg Gynecol Obstet 1975;141:429-437. [PubMed: 1162576]

20. Starzl TE, Koep LJ, Weil R, et al. Right trisegmentectomy for hepatic neoplasm. Surg Gynecol Obstet 1980;150:208-213. [PubMed: 7352313]

21. Starzl TE, Iwatsuki S, Shaw BW, et al. Left hepatic trisegmentectomy. Surg Gynecol Obstet 1982;155:21-27. [PubMed: 6283687]

22. Blumgart, LH. Liver resection: liver and biliary tumors. In: Blumgart, LH., editor. Surgery of the Liver and Biliary Tract. Edinburgh: Churchill Livingstone; 1988. p. 1251-1280.

23. Starzl TE, Iwatsuki S, Van Thiel DH, et al. Evolution of liver transplantation. Hepatology 1982;2:614636. [PubMed: 6749635] 
24. Iwatsuki S, Starzl TE, Todo S, et al. Experience in 1,000 liver transplants under cyclosporin-steroid therapy: a surgical report. Transplant Proc 1988;20:498-504. [PubMed: 3279643]

25. Fung JJ, Eliasziw M, Todo S, et al. The Pittsburgh randomized trial of Tracolimus compared to cyclosporin for hepatic transplantation. J Am Coll Surg 1996;183:117-125. [PubMed: 8696542]

26. Fisher, LD.; Van Belle, G. A methodology for the health sciences. In: Barnett, V.; Bradley, RA.; Fisher, NI., et al., editors. Biostatistics. New York: J. Wiley and Sons, Inc; 1993. p. 807-808.

27. Edmondson HA, Steiner PE. Primary carcinoma of the liver. A study of 100 cases among 48,900 necropsies. Cancer 1954;51:462-503. [PubMed: 13160935]

28. Altemeier WA, Gall EA, Zinniger MM, Hoxworth LH. Sclerosing carcinoma of the major intrahepatic ducts. Arch Surg 1957;75:450-461.

29. Nakajima T, Kondo Y, Mivazaki M, Okui K. A histopathologic study of 102 cases of intrahepatic cholangiocarcinoma: histologic classification and modes of spreading. Hum Pathol 1988;19:12281234. [PubMed: 2844646]

30. Klatskin G. Adenocarcinoma of the hepatic duct at its bifurcation within the porta hepatis: an unusual tumor with distinctive clinical pathological features. Am J Med 1965;38:241-256. [PubMed: 14256720]

31. Haug CE, Jenkins RL, Rohrer RJ, et al. Liver transplantation for primary hepatic cancer. Transplantation 1992;53:376-382. [PubMed: 1310823]

32. Olthoff KM, Millis LM, Rosove MH, et al. Is liver transplantation justified for treatment of hepatic malignancies? Arch Surg 1990;125:1261-1268. [PubMed: 2171452]

33. O'Grady JG, Polson RJ, Rolles K, et al. Liver transplantation for malignant disease. Results in 93 consecutive patients. Ann Surg 1988;207:373-379. [PubMed: 2451484]

34. Iwatsuki S, Starzl TE, Sheahan DG, et al. Hepatic resection versus transplantation for hepatocellular carcinoma. Ann Surg 1991;214:221-229. [PubMed: 1656903] 


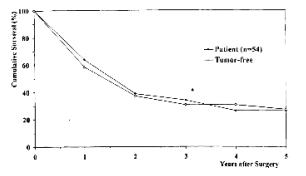

FIG 1.

Actuarial (overall) patient and tumor-free survival. 


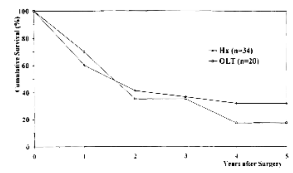

FIG 2.

Actuarial patient survival. Hx, hepatic resection; OLT, orthotopic liver transplantation. 


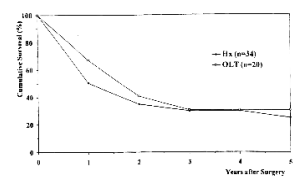

FIG 3.

Actuarial tumor-free survival. Hx, hepatic resection; OLT, orthotopic liver transplantation. 


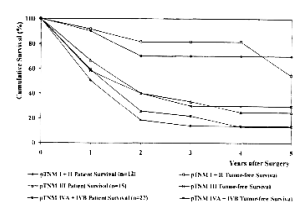

FIG 4.

Patient and tumor-tree survival by TNM stage. 


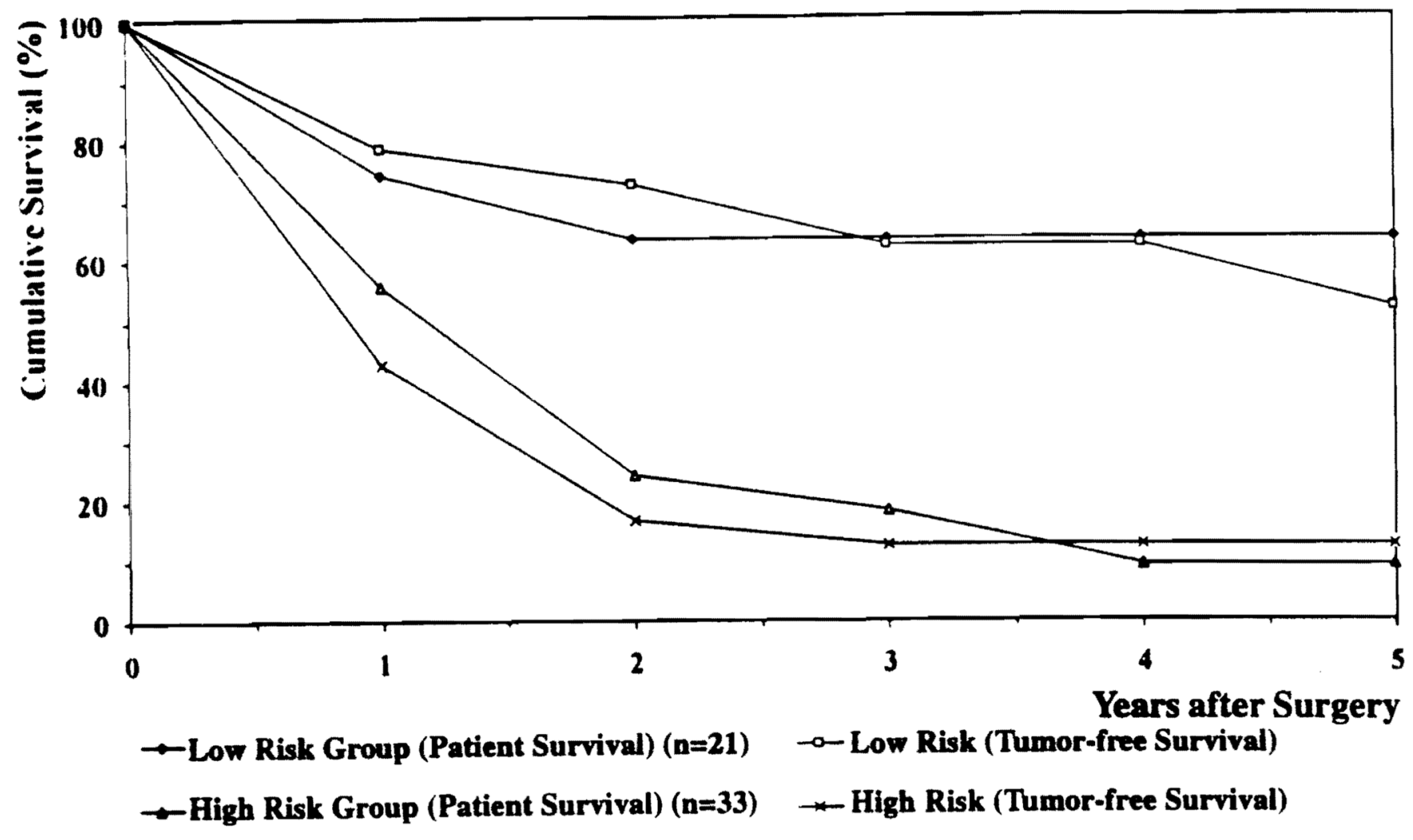

FIG 5.

Actuarial patient and tumor-free survival of low- and high-risk groups. 


\section{Table 1}

pTNM Pathologic Classification

\begin{tabular}{|c|c|c|c|}
\hline Stage I & $\mathrm{T}^{*}{ }^{*}$ & No & M0 \\
\hline \multirow[t]{2}{*}{ Stage II } & $\mathrm{T} 2^{\dagger}$ & No & M0 \\
\hline & $\mathrm{T} 1$ & $\mathrm{~N} 1 \%$ & M0 \\
\hline \multirow[t]{2}{*}{ Stage III } & $\mathrm{T} 2$ & $\mathrm{~N} 1$ & M0 \\
\hline & $\mathrm{T} 3 \S$ & $\mathrm{N} 0, \mathrm{~N} 1$ & M0 \\
\hline Stage IVA & $\mathrm{T} 4 / /$ & Any N & M0 \\
\hline Stage IVB & Any $\mathrm{T}$ & Any N & M1 Il \\
\hline
\end{tabular}

T1: solitary, $\leq 2 \mathrm{~cm}$, without vascular invasion.

${ }^{\dagger}$ T2: solitary, $\leq 2 \mathrm{~cm}$, with vascular invasion. Multiple, one lobe, $\leq 2 \mathrm{~cm}$, without vascular invasion. Solitary, $>2 \mathrm{~cm}$, without vascular invasion. ${ }^{+} \mathrm{N} 1$ : regional.

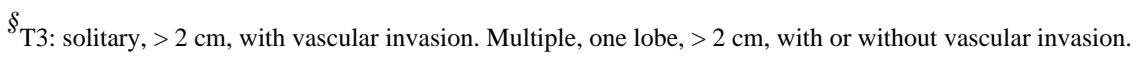

"T4: Multiple, more than one lobe. Invasion of major branch of portal or hepatic veins.

II M1: Distant metastasis. 


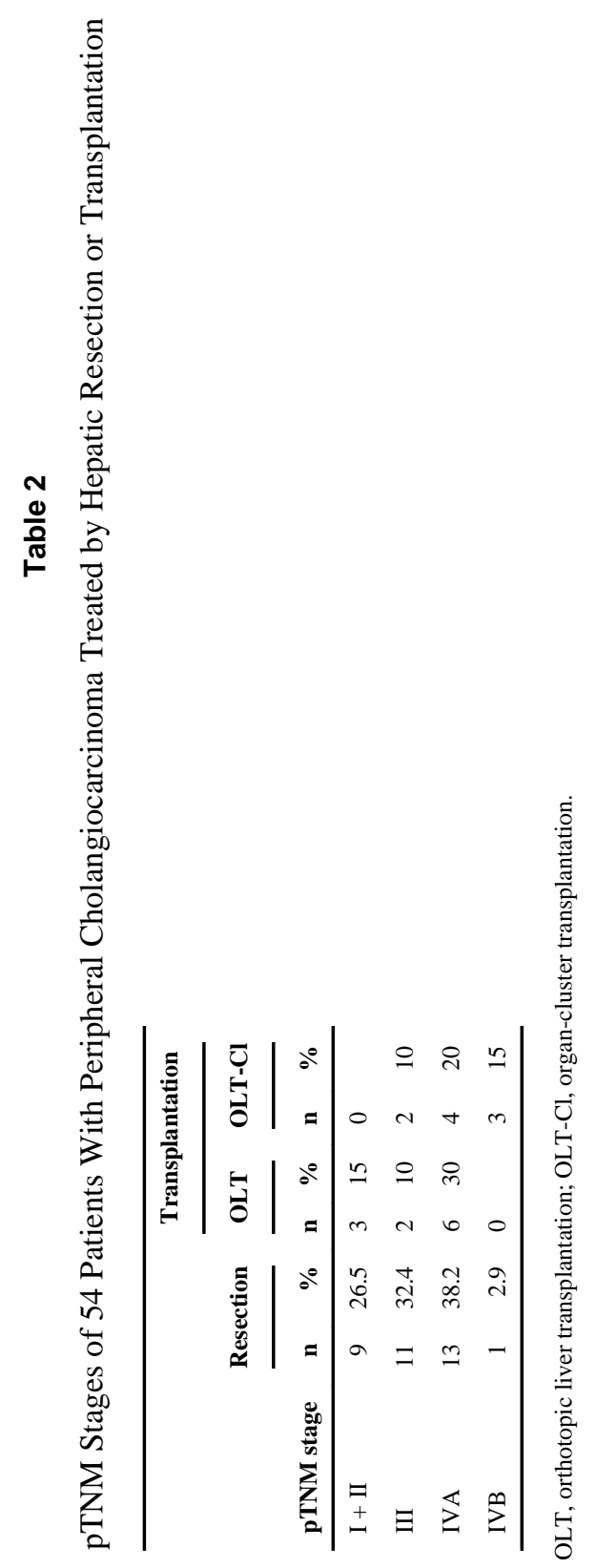

J Am Coll Surg. Author manuscript; available in PMC 2010 October 21. 


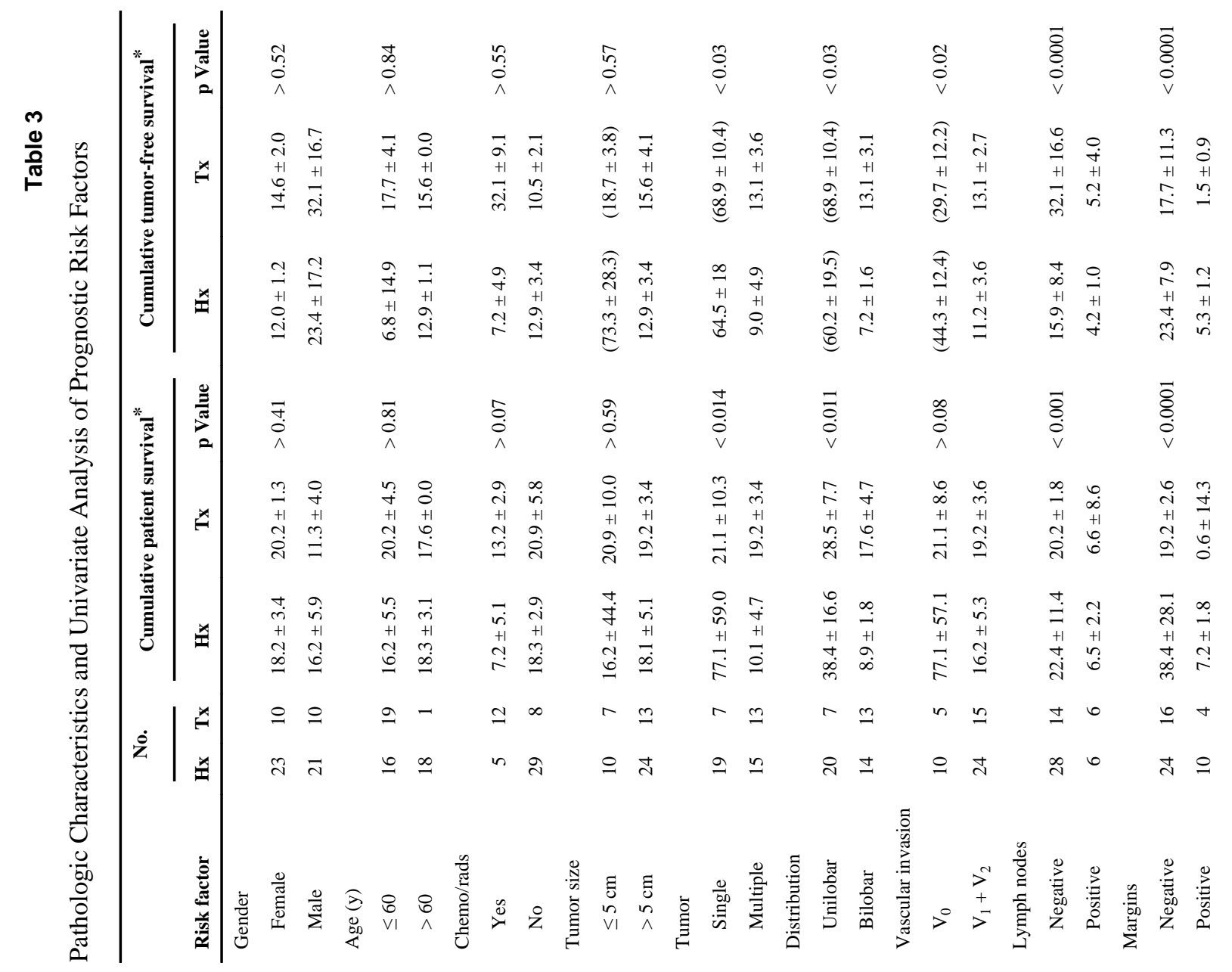




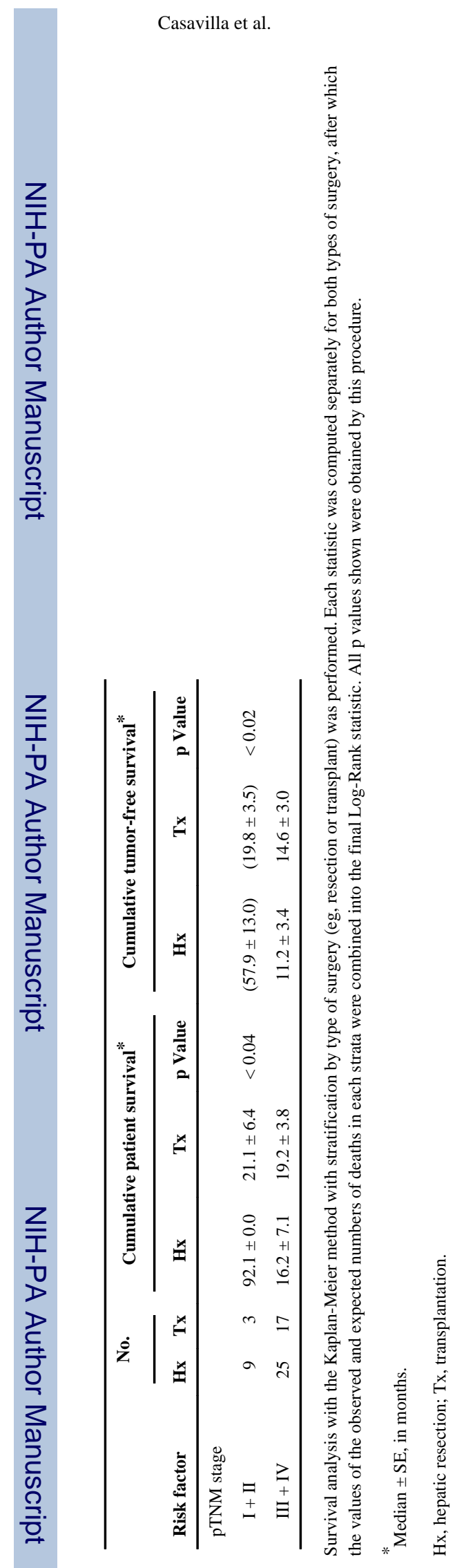

J Am Coll Surg. Author manuscript; available in PMC 2010 October 21. 